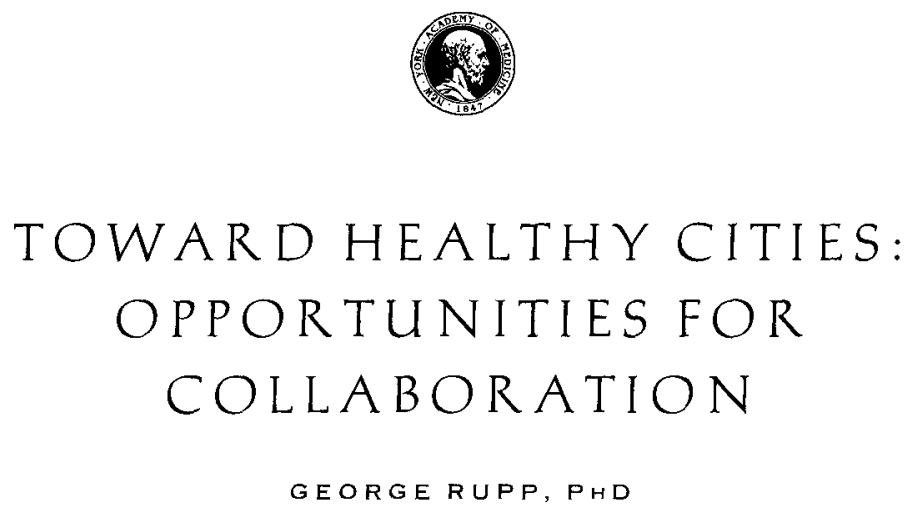

ABSTRACT This paper locates the need for an urban health agenda in a broader social context. This broader context is characterized by increasing diversity and extensive privatization-developments that accentuate tendencies leading away from a shared sense of the common good. The paper then outlines ways that Columbia University seeks to work for healthier cities in this challenging context.

\title{
THE SOCIAL CONTEXT OF URBAN HEALTH
}

The travails of public health in our time are a microcosm of our larger social world. Everywhere, public purposes are relegated to secondary consideration or even denigrated entirely. We as a society are losing a shared sense of the common good, of a public interest that surpasses private interests.

Appeals to the common good as a check on individual ambition and personal aggrandizement are, of course, perennials in rhetoric that ranges from political populism to religious exhortation, so we should not exaggerate the novelty of our situation. Still, there are developments that accentuate tendencies leading away from a shared sense of the common good. I will note two such developments: increasing diversity in our society and extensive privatization of public responsibilities.

\section{Diversity}

Pluralism of social and cultural traditions has been a fact of our American life since our founding. It is central to the deliberations that led to the framing of our Constitution. As Hamilton and Madison and Jay argued vigorously in the Federalist Papers, "the violence of faction" was a constant threat to popular democracy. The Constitution was designed to control this danger by a series of checks and balances that prevented a minority from exercising undue influence, while

Dr. Rupp is President, Columbia University, 202 Low Memorial Library, New York, NY 10027 
also allowing for the expression of all points of view. In particular, religious diversity was allowed for, with the explicit proscription of official endorsement-or establishment-of any one religious position or community.

Despite this acknowledgement of pluralism in principle, for much of American history there has been a broadly accepted framework for representing and affirming common values. For the Founders, this shared framework was a kind of panProtestantism that included Deism and even more attenuated forms of secular piety. Combining Biblical and Republican traditions, the rhetoric of American public life has not unfairly been characterized as a "civil religion," a tendency that no doubt finds its eloquent expression in the figure of Abraham Lincoln.

Certainly, the limitations of pan-Protestantism as a foundation for American civil religion have been evident for some time. But, even as recently as the 1950s, observers who described the pluralism of American religious traditions still surveyed a quite limited diversity. Will Herberg's influential book, Protestant, Catholic, Jew (1955), illustrates this double fact: insistence that traditions in addition to Protestant ones must be acknowledged, but little awareness of diversity beyond a quite homogenized view of Catholics and Jews.

How much our situation has changed since the 1950s! It is not only that others are more visible and vocal: Muslims, Hindus, Buddhists, and those, including agnostics, atheists, and secularists, who range between indifference and hostility to religion. It is also that we are much more acutely aware of internal differences within nominally unified communities, certainly including within Protestantism, Judaism, and even Catholicism. And, because this religious pluralism often overlaps with racial, ethnic, and class differences, it becomes all the easier to identify with one community against the society as a whole and thereby tacitly to define some of our fellow citizens as outside the circle of our concern.

This awareness of diversity, and even exclusion, is only sharpened when a particular movement like the religious right attempts to return to a time when a unified civil religion was accepted unapologetically-or even to establish for the first time explicitly Christian convictions as the official American credo. Among those who find this position unattractive are not only atheists, agnostics, and secularists, but also adherents of other-than-Christian communities and many Christians themselves, as well as racial and ethnic minorities not included in the portrait of the past that is evoked and celebrated. Thus, the attempt to restate an allegedly broad framework for representing and affirming common values serves instead to call attention to just how great the diversity of our society has become.

This greatly increased diversity and the even more dramatically heightened awareness of it fracture any sense of a unified community and, therefore, render 
all the more dubious any aspiration to express a shared sense of the common good. There have been times when a confident secular liberalism claimed the ability to address public issues in compelling ways that in turn relegated religious, ethnic, and other more particular traditions to the private sphere. However, confidence in this ability on the part of secular liberalism has all but collapsed, which only deepens our contemporary dilemma.

\section{Privatization}

Reinforcing the impact of pervasive pluralism are initiatives to privatize wide ranges of public life-initiatives that are all the more threatening because they come at a time of increasing polarization in the distribution of wealth. With the demise of Communism, our celebration of the dynamism and efficiency of markets has just about drowned out any appeal to the public interest as more than the sum of private interests. Through the two titanic struggles that have dominated this century-World War II and the cold war-we have learned to distrust totalitarian visions of the common good, no matter what they promise. The pervasive pluralism of our contemporary situation seems to confirm the hopelessness of agreement on any particular sense of the common good. It is, therefore, tempting to resign ourselves to-if not rejoice in-the power of markets to deliver the goods and perhaps even to generate compelling visions of the good life that are more widely shared than any of the competing alternatives.

Here, again, we must not exaggerate the novelty of our situation. At least since Adam Smith, there have been serious thinkers who advanced the view that disciplined pursuit of personal interests was the most productive way to enhance society as a whole. What does differ, though, is the context for such claims. Smith presupposed a tradition of inquiry in which humans were imbued with what he called "a moral sense" that shaped their behavior and assured a concern for the larger community. This whole moral and philosophical tradition is utterly absent from current celebrations of the market.

Most of us cannot rely unquestioningly on a moral sense allegedly inherent in every human any more than we can, without further ado, appeal to a sense of the common good purportedly shared across a bewilderingly diverse array of traditions. Accordingly, it becomes a challenge, rather than simply a given, to attain a sense of inclusive community and of the common good for that community. To meet this challenge is crucial as we work together to harness the power of markets for public purposes.

The delivery of what have been, for the most part and for centuries, public services illustrates the need to address this challenge. Education is perhaps the most fundamental case in point. Other examples are the provision of security, 
transportation, and sanitation. In each instance, private alternatives may provide bases for comparison and accountability; privatization may generate efficiencies and savings. Those are substantial achievements, but we all know that when education, security, transportation, and sanitation are privatized, the larger society is not automatically well served, even when individuals or particular communities benefit because they are insulated from other communities or even walled off, with access only through guarded gates. We must, therefore, identify and keep our focus on the common good to be realized; we must keep in focus the end toward which greater efficiency is the means, the public interest to which the process of privatization is responsible.

This need is nowhere more critical than in the delivery of health care. Nor is the disjunction between private and public any greater anywhere than it is between individual and social health. We have what is indisputably the best tertiary care medicine in the world, and we also have the highest rate of infant mortality among advanced industrial societies. Or, even more stunning, in Harlem there is less than 1 doctor per 10,000 people; on the upper East Side, the figure is 1 doctor for each 60 people.

\section{PUBLIC HEALTH AND THE CONTRIBUTIONS OF THE UNIVERSITY TO IT}

In deliberations about the delivery of medical care, the very conception of public health provides a critical contribution. Medical care is too often construed far too narrowly as directed to individuals. Even when the focus is not exclusively on the treatment of disease and instead includes preventive medicine and the maintenance of health, the central preoccupation is with the individual. Ironically, this focus is still evident in health maintenance organizations. For business purposes (economics of scale, spreading of risk, etc.), large numbers of people are involved, but the unit of analysis is the individual covered life, albeit aggregated into large populations.

In contrast, public health affords the prospect of including consideration of the well-being of the larger society-in principle, the society as a whole. This perspective is especially critical insofar as my characterization of our current situation is accurate, namely, as a time when religious, racial, and ethnic diversity fractures a sense of unified community and when increasing polarization in the distribution of wealth makes talk of privatization all the more threatening. In this situation, disciplined reflection on public health, on the well-being of the society as a whole, is invaluable in pursuing an urban health agenda-a task that Columbia University addresses in a variety of ways.

The most direct contribution that Columbia University makes to the urban 
health agenda is through the work of its School of Public Health (SPH). Even a list of a few instances may serve to indicate the range of efforts under way in the area of urban health, construed as the vitality of our cities:

- Best Beginnings, a partnership that connects university, city, and community organizations, focuses on preventing child abuse, reducing the need for special schooling, and lowering school dropout rates.

- The Northern Manhattan Women and Children's Project is a one-stop health care provider that serves 7,500 people.

- The Comprehensive Adolescent School-Based Health Program operates five clinics that provide medical health, social work, and health education services and provides more than 35,000 visits per year.

- The Young Men's Clinic provides over 1,000 young men with health and social services.

- In the Harlem Center for Health Promotion and Disease Prevention, the SPH collaborates with Harlem Hospital, the university's College of Physicians and Surgeons, and its Schools of Nursing and Oral and Dental Surgery to test a variety of intervention strategies.

- In a new center for Environmental Health funded by the National Institutes of Health, the SPH brings together not only our health sciences, but also the Lamont-Doherty Earth Observatory to address the environmental causes of disease in underprivileged populations.

There are many more such initiatives under the auspices of the School of Public Health. In many community projects, the Schools of Nursing and Oral and Dental Surgery and the College of Physicians and Surgeons are energetic partners and also sponsor clinics and other programs of their own. Put bluntly, the public health of northern Manhattan would be even more precarious without the concerted efforts of all of our four health sciences schools.

Also, beyond programs in the health sciences, Columbia University is a committed advocate for urban health. Here are just a very few examples. The Law School offers an impressive array of legal services for those who can pay little or nothing for them. The Business School counsels with small business ventures in Harlem. The School of Social Work and our Urban Planning program in the School of Architecture provide extensive services and learning opportunities in our urban neighborhoods.

Columbians were centrally involved in drafting the proposal that was funded as the Upper Manhattan Empowerment Zone, and, with the help of funding from the Ford Foundation, we continue to provide assistance to the Empowerment Zone. On the model of the agricultural extension service developed in our 
great Land Grant Universities, we have established an Urban Technical Assistance Project that is located in Harlem and provides analytical and support services to community organizations. With support from the federal government, we have connected six Harlem schools to our computing facilities, including access to the Internet; we are now working with the City Department of Education to develop a network that includes 46 schools.

In its construction and purchasing, Columbia University is taking systematic steps to identify vendors and contractors based in Morningside Heights, Washington Heights, and Harlem so that we participate as positively as we can in the economic life of our community.

Such programs are designed to open opportunities to those who have too often not had access to them. An excellent example of this intention is our Double Discovery Program, the oldest continuing upward program in the country, which in 1996 celebrated its 30th anniversary. Double Discovery begins with students in junior high school through its talent search program. Working one on one and in small groups, Double Discovery reaches 1,000 low-income students a year and provides intensive academic help and college preparation assistance. Double Discovery students enroll in college at a remarkable rate of $98 \%$. What is especially gratifying is that not only the students, but also the volunteers, experience the enlargement of their world.

The same experience is evident in our largest volunteer program, Community Impact. Each semester, over 800 students and also some faculty and staff contribute their time, energy, and talents to a wide range of educational, social action, and community service organizations, mostly in Morningside Heights and central Harlem. The direct contributions they make to those organizations and the people they help are substantial. Also as significant are the ways the participants themselves are changed as they come to expand the boundaries of their experience and also the circumference of the circle that they include in their concern.

\section{CONCLUSION}

The examples above illustrate a central point: at a time when religious, racial, and ethnic diversity fractures a sense of unified community, such programs help to achieve a sense of membership in a common body. At a time when privatization threatens to differentiate quality of service as the counterpart of an increasingly polarized distribution of wealth, such programs span divisions that desperately need to be bridged. While this contribution does not directly and immediately add to public health narrowly construed, it is utterly indispensable if we are to advance an urban health agenda over the long haul. 